\title{
3D Foot Model for Women Who Wear Smaller Size Shoes
}

\author{
Yuanfang ZHAO \& Li Li* \\ Department of Institute of Textiles and Clothing, The Hong Kong Polytechnic University, Hong Kong
}

Submission: October 03, 2017; Published: December 01, 2017

*Corresponding author: Li Li, Institute of Textiles and Clothing, The Hong Kong Polytechnic University, Hong Kong, Tel: (852) 2744 4106; Email: li.lilly@polyu.edu.hk

\begin{abstract}
Adult women who have Smaller Size Feet (SSF) suffered a lot when purchasing shoes for proper size and fit. Most of them can only wear sneakers with shoelace or select some shoes in children's section due to the right size. However, these shoes are improper for them. Despite the limitation of style option, the shoes may cause uncomfortableness even severe consequence when wearing constantly. This study aims to prove that the 3D foot model of women who have Smaller Size Feet (SSF) is different from children's measurements and also different from the model scaled down from normal women size. A newly designed prototype will be made for wear trial and assessment.
\end{abstract}

\section{Introduction}

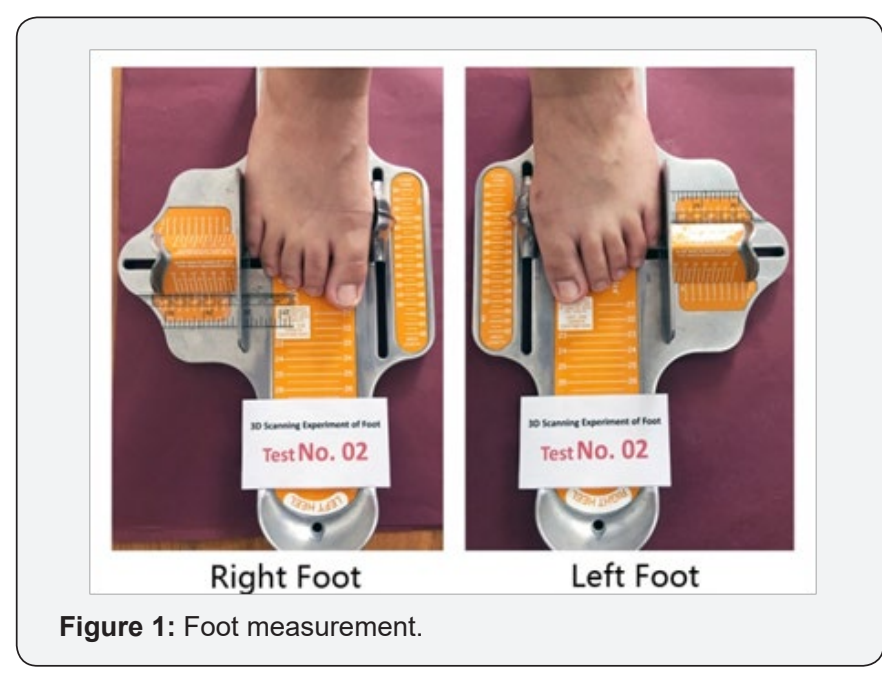

There are lots of women who have smaller feet than normal women. No precise statistic states the figure now. So far, this group of people has not drawn any attention to the researchers. It is difficult to find one solid research focuses on this group of people and the wearing condition they are facing. However, this does not mean they are few in number or did not suffer a lot. Lee and Wang scanned 1000 female in Taiwan to collect 3D foot shape data [1]. (Figure 1) shows that there are at least 40 females who have feet smaller than $220 \mathrm{~mm}$ (US size 5, China size 34 ).

The plights of women who take a small shoe size need comfort, style and selection as normal women do. It's easy to suggest shopping in the children's section, however, the style design, color choices are incredibly limited. Kids would better wear ballet flats and be fond of Barbie pink and big bows, which are to some extent inappropriate for adult women. SSF women prefer all kinds of flats, high heels, sandals, boots rather than just sneakers with shoelace. Many women shared their inner voice and experience in the internet, one blogger named Luwam Yeibio wrote article to share her suffer and the method to buy small size shoes in 2012 [2]. Like Ms. Yeibio, SSF women want wear shoes with right size and proper fit instead of suffered two insoles in the shoe or balls of tissues ahead of the toes. These customers keenly need to be satisfied. For instance, a shop in Taobao as shows in (Figure 2), which provides smaller size shoes for women. During the last 30 days, this kind of shoes in (Figure 2) sold 26 pairs lists in (Figure 3), of which 13 pairs were size 31-33 [3].

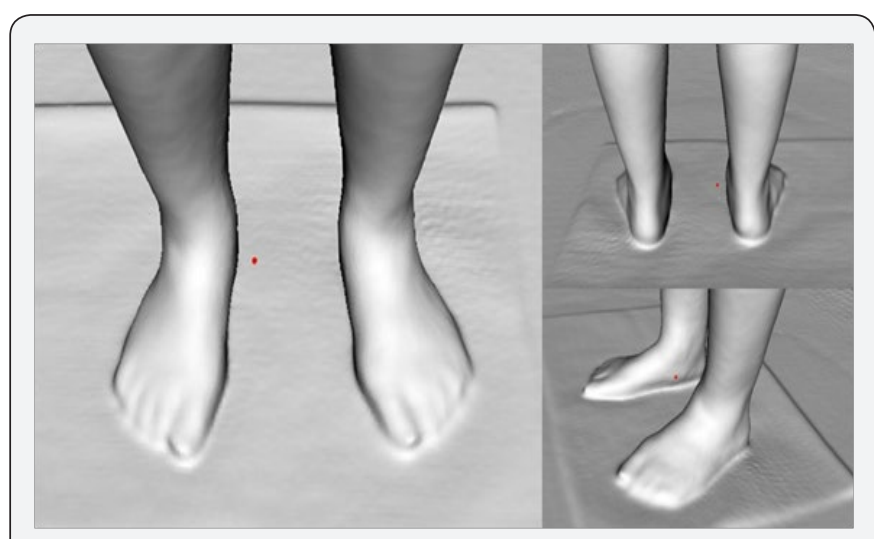

Figure 2: 3D foot images.

Limited research can be found on consequences caused by wearing children shoe as a substitute of smaller shoe. However, abundant researches have proved that wearing improper shoes can cause different consequences. Children's shoe may be too tight, too narrow or any other problems to result in improper fit. Proper shoe size is an important element of foot health. Shoes 
that are too small increase pressure on the foot, and those that are too large cause friction from sliding of the foot [4]. Shoes should reduce pressure, shear and shock forces from the foot $[5,6]$. Wearing shoes that are not appropriate for the foot shape and size can damage health even can cause a variety of diseases. A lot of clinical symptoms, such as bunion, corn, cysts, hammer toes, plantar fasciitis, and heel pain are caused by wearing improper shoes. When wearing too tight or too narrow shoes, the friction between feet and shoes is intensified. This will cause swelling, pain, even leads to the problems of ankle, knee, hip and back. Women who wear improper shoes are putting them at risk for corns, bunions, and other deformities that may require surgery to correct $[7,8]$. It is essential that a shoe fit both the length and width of the foot.
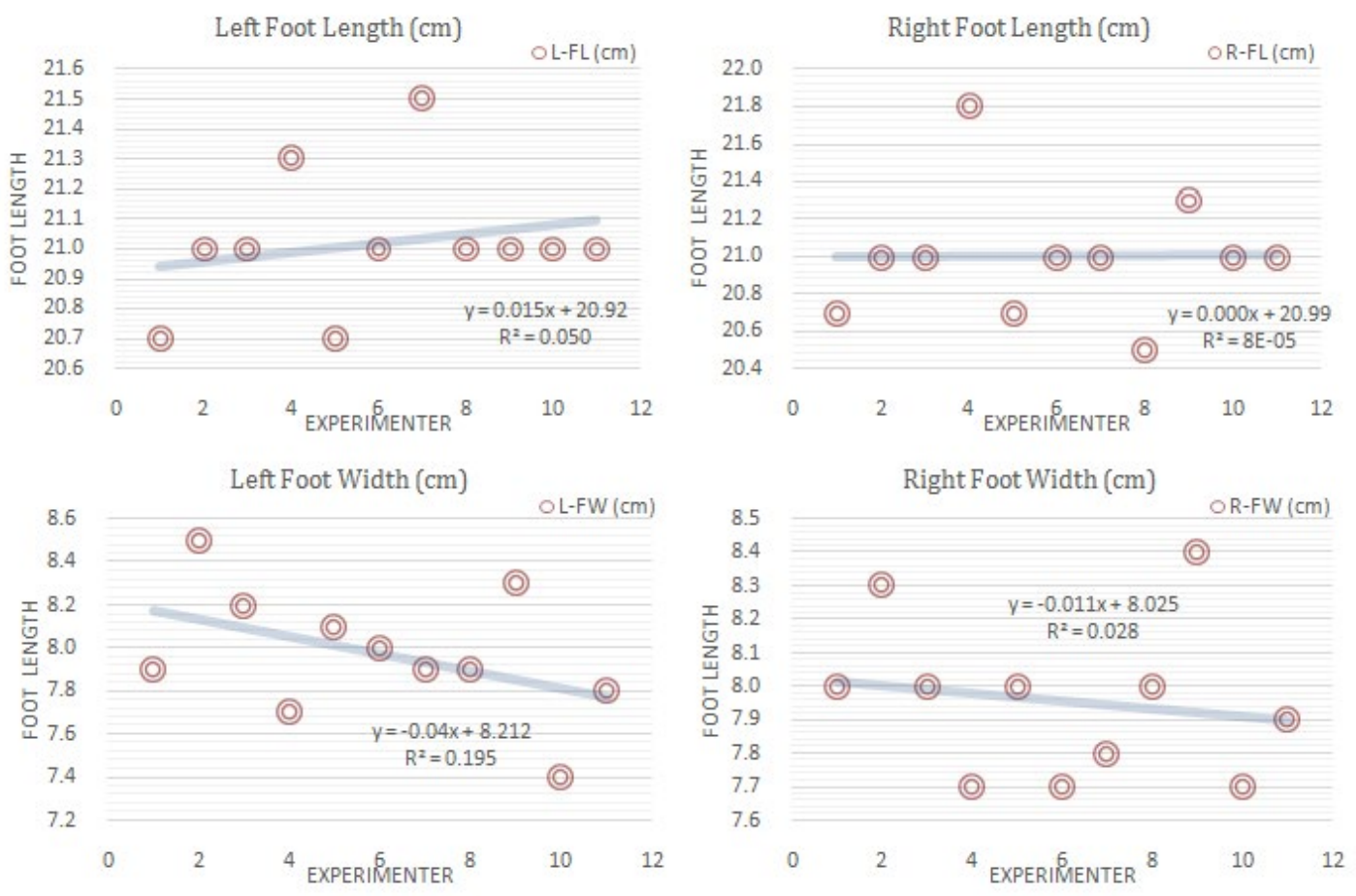

Figure 3: Foot Length and Foot Width of Experimenter.

Proper size is an important element of foot health, which can provide foot protection and stability [9]. Kolarik [10] pointed out that " The customer will judge his or her shoe fit by wearing the shoes, but at the factory we must use "substitute " characteristic like length, width, and so on, to design, develop and produce our product" [10]. The most appropriate question is usually in the "width" dimension since the commonly used system of shoe sizing is about length. Narrow shoes always cause foot pain or discomfort in the ball area. So far, ergonomists have been trying to achieve the correct fit between people and the tools or equipment they use. However, footwear manufacturers have not developed a quality evaluation system for the fit between feet and shoes [11]. With the advancement of optoelectronic technologies, 3D scanning technique becomes a more precise approach than the conventional manual anthropometric data collection methods [12]. Using 3D scanning technique to making shoe-last can help to achieve proper shoe size.

\section{Experiments Design}

\section{Participants}

A total of 11 Chinese female women from Shenzhen were involved in 3D foot scanning. The 3D foot scanning data were collected during November 2015. This newly obtained foot anthropometric database will be used in this study. The age of the subjects ranged from 18 to 41 years. All participants have a feet length around $210 \mathrm{~mm}$. None of the participants had any history of visible foot abnormalities or foot illnesses.

\section{Equipment}

Tapeline and foot measurement device were used in the foot measurement experiment. Kinect camera and laptop were used for 3D scanning process [13]. Artec studio 9 was the software to create the 3D scanning images. The 3D point cloud data was processed and analyzed using MATLAB.

\section{Experiment procedure}

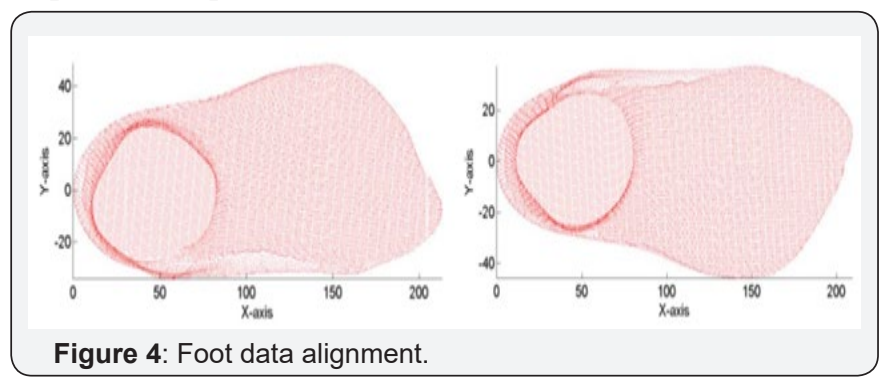


Foot measurement: Both feet of each experimenter was manually measured by foot measurement device showed in (Figure 3) to record their foot length, foot width and arch length. Ball firth was measured by tapeline separately.

3D scanning: Firstly, the target feet were scanned by Kinect camera in 360 degrees. Secondly, the raw scanning images were displayed in Artec software. Then, 3D foot images were created by running the program. Lastly, the 3D foot image needed to be carefully checked to confirm it met the requirement. Each experimenter needed to scan three times in a natural standing posture without support. The body weight is distributed evenly on both feet.

Table 1: Basic demographic data of the participants.

\section{Results and Analysis}

\section{Statistic analysis}
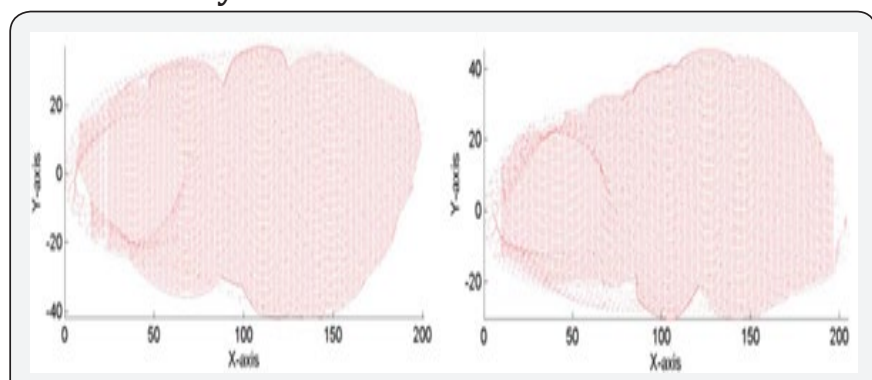

Figure 5: Bad data (Sample No.10).

\begin{tabular}{|c|c|c|c|c|c|c|c|c|c|}
\hline & \multicolumn{9}{|c|}{ Females $(n=11)$} \\
\hline Term & Mean & & Max & & & Min & & SD & \\
\hline Ages (years) & 28 & & 41 & & & 18 & & 5.26 & \\
\hline Height $(\mathrm{cm})$ & 149.7 & & 157 & & & 145 & & 4.24 & \\
\hline Weight (kg) & 46.9 & & 63 & & & 37 & & 7.65 & \\
\hline \multicolumn{4}{|c|}{ Right Foot } & & & \multicolumn{4}{|c|}{ Left Foot } \\
\hline Term & Mean & Max & & Min & SD & Mean & Max & Min & SD \\
\hline $\begin{array}{l}\text { Foot length } \\
\text { (mm) }\end{array}$ & 210 & 218 & & 205 & 3.41 & 210.2 & 215 & 207 & 2.27 \\
\hline $\begin{array}{l}\text { Foot width } \\
\quad(\mathrm{mm})\end{array}$ & 79.5 & 84 & & 77 & 2.34 & 79.7 & 85 & 74 & 3 \\
\hline $\begin{array}{l}\text { Ball girth } \\
\text { (mm) }\end{array}$ & 193.3 & 210 & & 180 & 8.64 & 193.6 & 210 & 180 & 9.1 \\
\hline $\begin{array}{l}\text { Arch Length } \\
\quad(\mathrm{mm})\end{array}$ & 208.5 & 223 & & 203 & 5.79 & 208.8 & 219 & 202 & 5.64 \\
\hline
\end{tabular}

Basic demographic data of the participants were analyzed. Four foot dimensions including foot length, foot width, ball girth and arch length were collected as shown in (Figure 4). The means and standard deviations of the four dimensions were presented in Table 1.

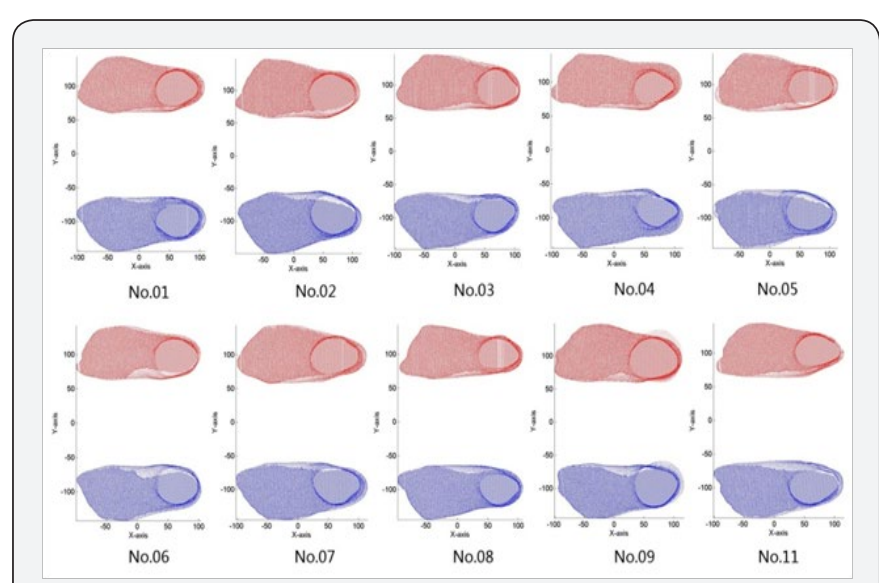

Figure 6: Corrected 3D model data.

\section{D foot model}

Twenty two 3D scanning images of women experimenters were aligned along heel center line, which was defined as the line separating the heel to equal halves in the heel region [14] respectively as showed in (Figure 5). To be noticed, sample No.10 (Figure 6) were finally eliminated for being bad data. The outline of foot was not smooth and accurate which would affect the average model.

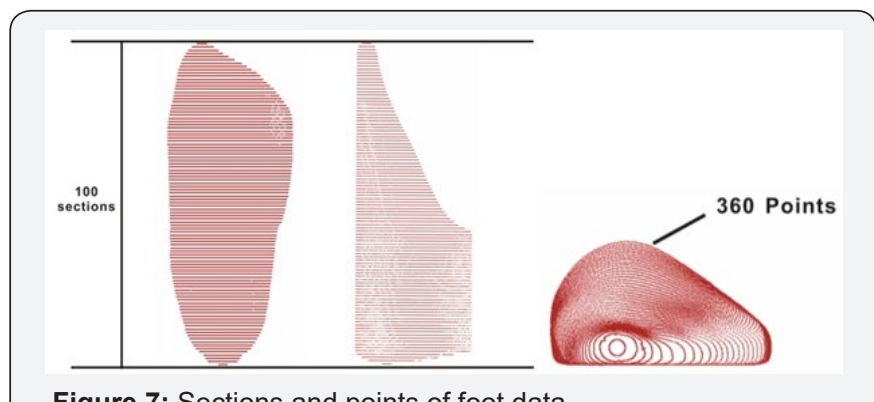

Figure 7: Sections and points of foot data.

As listed in (Figure 7), the data need to be correct and classified by each experimenter after the alignment of each foot.

As demonstrated in (Figure 8), using prediction method presented by A. Luximon et al. [15], the aligned foot was sectioned at each $1 \%$ foot length so that there were 100 sections. The points of each section were then sampled at a fixed angular interval of 18 so that there were 360 points per section. Hence each foot had points with coordinates $\mathrm{pij}=(\mathrm{xij}, \mathrm{yij}, \mathrm{zij})$, where $i=1, \ldots, 100 ; j=1, \ldots, 360$. 


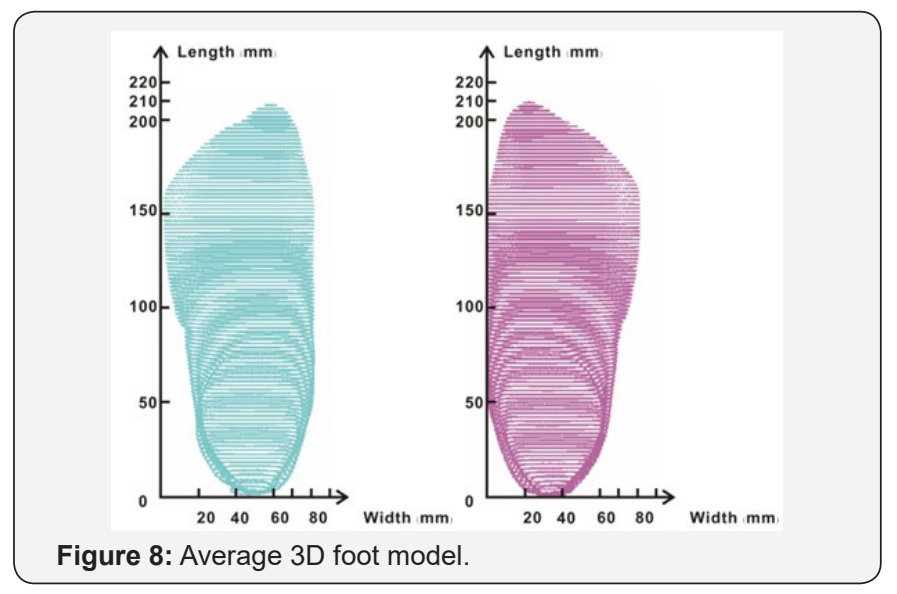

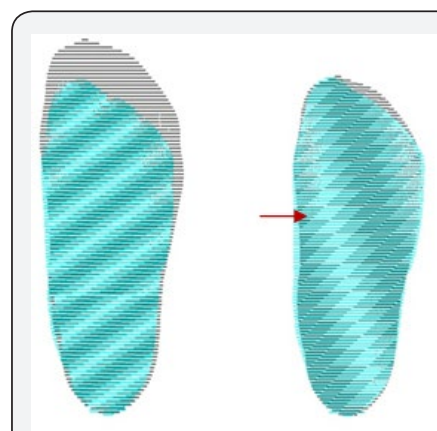

Left Foot

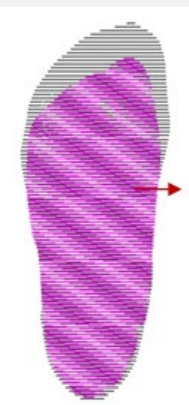

Right Foot

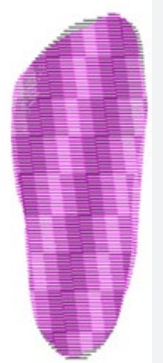

Figure 9: Scale down average 3D foot model of normal women.

Averaging the points of different subjects created the average foot model as showed in (Figure 9). The blue one is the average model of left foot and the pink one is the one for right foot. The length of the left foot model and right foot model is $210.36 \mathrm{~mm}$ and $209.29 \mathrm{~mm}$ respectively. The width of each foot is $82.46 \mathrm{~mm}$ and $82 \mathrm{~mm}$ respectively.

\section{Discussion}

\section{Comparison to average 3D foot model of normal} women
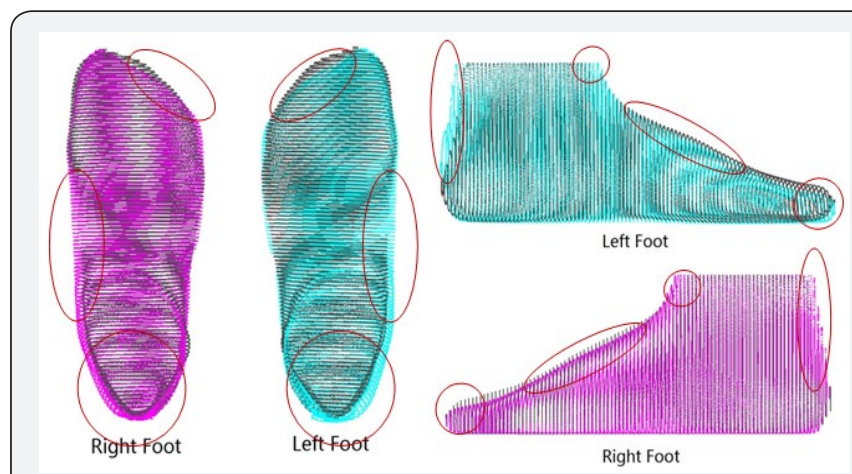

Figure 10: Comparison of two 3D foot models.

A 3D model of Normal women (NF) was generated by using 100 sample data of size $230 \mathrm{~mm}$, which is the grey foot print in (Figure 10). For comparing purpose, the NF model needed to be scaled down to $210 \mathrm{~mm}$ to compare with the average 3D model of SSF women.

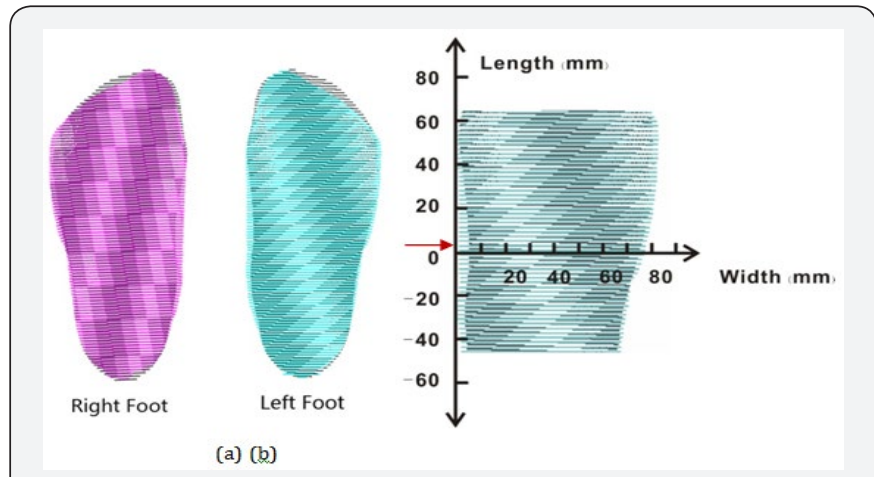

Figure 11: (a) Bottom view of the comparison of two 3D foot models; (b) Deviation of instep part of left foot

After scaling down, the differences between these two models were quite obvious. The red circle parts in (Figure 11) were showed the significant difference. Both feet had similar deviation parts. Take the left foot for example, the SSF model (blue color) had pointed toe than NF model (grey color). Also, the arch height and toe height of SSF model were lower. The width of instep of SSF model was much wider. The girth of ankle of SSF model was much larger as well [16].

Table 2: Comparison of average 3D foot model.

\begin{tabular}{|c|c|c|c|c|c|}
\hline SSF & & $\begin{array}{c}\text { NF (Scaled } \\
\text { down) }\end{array}$ & & $\begin{array}{c}\text { Width } \\
\text { Deviation }\end{array}$ & \\
\hline & $\begin{array}{c}\text { Length } \\
\text { (mm) }\end{array}$ & Width (mm) & $\begin{array}{c}\text { Length } \\
\text { (mm) }\end{array}$ & $\begin{array}{c}\text { Width } \\
\text { (mm) }\end{array}$ & $(\%)$ \\
\hline Right Foot & 209.29 & 82 & 209.29 & 81.57 & $0.50 \%$ \\
\hline Left Foot & 210.36 & 82.46 & 210.36 & 81.36 & $1.35 \%$ \\
\hline
\end{tabular}
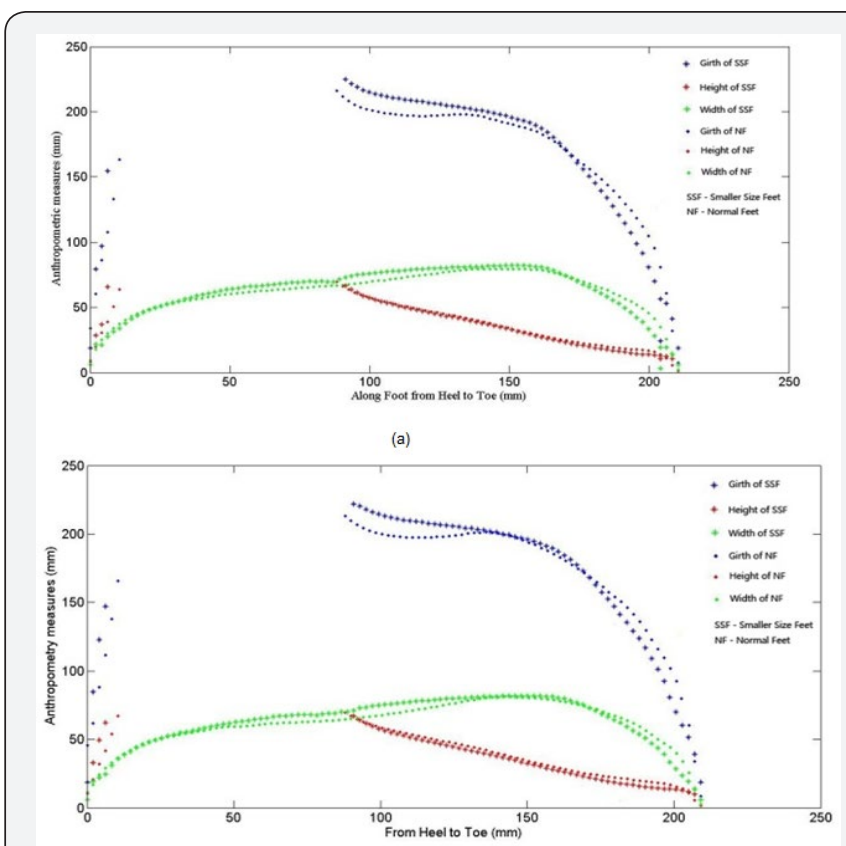

(b)

Figure 12: Difference in girth, height and width of right foot (a) and left foot (b). 
Comparing to the foot width of both models in Table 2, the deviation was $0.5 \%$ in right foot and $1.35 \%$ in left foot, which was not that significant when comparing to the deviation of instep part. As shown in the bottom view in (Figure 12), the deviation of instep foot width was quite significant. The maximum deviation even reached $11.4 \%$, which will be definitely put into consideration in shoe-last making and modifying.

Comparing the data of girth, height and width, the difference of them were showed in (Figure 12). Both feet have similar deviation. The star line was for SSF model and the dot line was for NF model. The blue color represented girth while the green is for width and red is for height. Take the right foot for example, the height of both model were similar. The width was different in toe part and instep part. The girth had significant difference in front part of the foot and instep part. To sum up, the instep part had major difference in width and girth.

\section{Conclusion}

This study successfully proved that the 3D foot model of women who have Smaller Size Feet (SSF) is different from the children's measurements. With the similar foot length, the foot width of children was $3.38 \%$ slimmer than the average data of SSF women. Although the foot lengths were similar, children had slimmer feet than adult women who have smaller feet. This study also successfully proved that the 3D foot model of SSF women is different from the model scaled down from normal women size. The front part, instep part, arch part and ankle part are all different. The biggest deviation in instep part can reach $11.4 \%$, which will be definitely put into consideration in shoe-last making and modifying.

\section{References}

1. Lee YC, Wang MJ (2015) Taiwanese adult foot shape classification using 3D scanning data. Ergonomics 58(3): 513-523.
2. Yeibio L (2012) Small Feet Confidential: I Have To Buy Shoes In The Kids' Department!, United States.

3. Smaller Size Shoes Store (2015) Taobao.

4. Schwarzkopf R, Perretta DJ, Russell TA, Sheskier SC (2011) Foot and Shoe Size Mismatch in Three Different New York City Populations. J Foot Ankle Surg 50(4): 391-394.

5. Janisse DJ (1992) The art and science of fitting shoes. Foot Ankle 13(5): 257-262.

6. Goonetilleke RS (2003) Designing footwear. In: Khalid HM, Lim TY, Lee NK (Eds.), Back to Asics in an effort to design for people. Malaysia: SEAMEC, pp. 25-31.

7. Goud A, Khurana B, Chiodo C, Weissman BN (2011) Women's musculoskeletal foot conditions exacerbated by shoe wear: an imaging perspective. Am J Orthop (Belle Mead NJ) 40(4): 183-191.

8. Fischer SJ, Haddad SL (2012) Tight Shoes and Foot Problems.

9. Robbins S, Waked E, Krouglicof N (1998) Improving balance. J Am Geriatr Soc 46(11): 1363-1370.

10. Kolarik WJ (1995) Creations Quality. New York: McGraw-Hill.

11. Goonetillekc RS, Luximon A, Tsui KL (2000) The Quality of Footwear Fit: What we know, don't know and should know. Proceedings of the Human Factors and Ergonomics Society Annual Meeting 44(12): 2-515-2-518.

12. Lu JM, Wang MJJ (2010) The Evaluation of Scan-derived Anthropometric Measurements. IEEE Transactions on Instrumentation and Measurement 59(8): 2048-2054.

13. Luximon A, Luximon Y (2009) Shoe-last design innovation for better shoe fitting. Computers in Industry 60(8): 621-628.

14. Luximon A, Goonetilleke RS (2004) Foot shape modelling. Hum Factors 46(2): 304- 315.

15. Luximon A, Goonetilleke RS, Zhang M (2005) 3D foot shape generation from 2D information. Ergonomics 48(6): 625-641.

16. Muller S, Carlsohn A, Muller J, Baur H, Mayer F (2012) Static and dynamic foot characteristics in children aged 1-13 years: a crosssectional study. Gait Posture 35(3): 389-394.

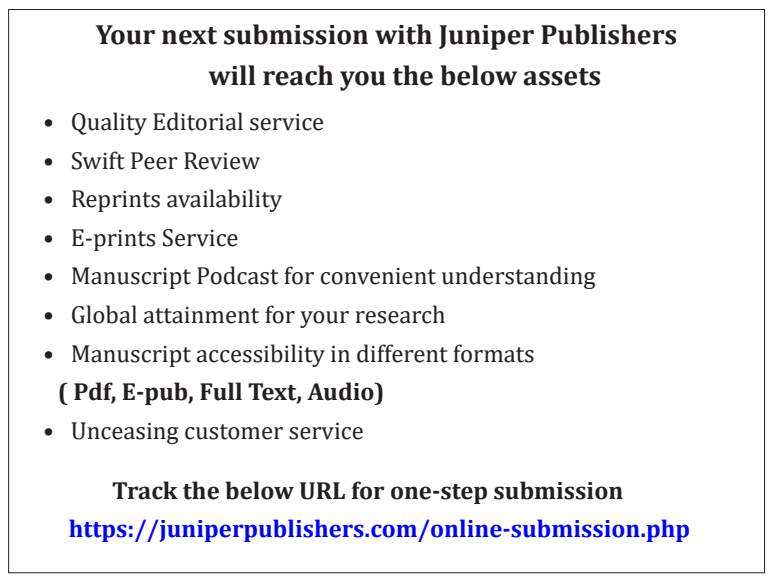

